\title{
PUSAT SUMBER BELAJAR GUGUS
}

\author{
Eva Betty Simanjuntak, Dewi Syafriani \\ Surel: elvimailani@unimed.ac.id
}

\begin{abstract}
The partners that are targeted by this service program are the Study Center Resource Centers (PSBG) Study Centers and Creative Parks located in Tebing tinggi city of North Sumatra Province. Based on observations and interviews with the PSBG administrators there are 5 problems faced by partners, including: (1) The teacher's ability to make teaching aids and catalogs is very low; (2) The use of IT contained in the CBD is very rare; (3) RPPs made by teachers have not included various learning models; and (4) The teacher has not been able to make a monthly PSBG magazine. Based on these problems, a number of solutions were offered, including: (1) training and mentoring to create learning media and their catalogs; (2) training and mentoring for making IT-based media; (3) training and mentoring to prepare lesson plans with various learning models; and (4) training and mentoring for the creation of the PSBG monthly magazine. Specific targets and outputs that will be produced are: (1) Catalog of learning media; (2) A collection of IT-based learning media; (3) Book collection of assessment rubrics. The method of implementing the service program will be carried out in a gradual, continuous and comprehensive manner carried out through clinical supervision methods in an effort to develop the capabilities and skills of managing and empowering the sustainability of the $C B C$.
\end{abstract}

Keywords: Revitalization, Cluster Learning Center, Based on IT

\begin{abstract}
ABSTRAK
Mitra yang menjadi sasaran program pengabdian ini adalah Pusat Sumber Belajar Gugus (PSBG) Study Center dan Taman Kreatif yang terdapat di kota Tebing tinggi Provinsi Sumatera Utara. Berdasarkan observasi dan wawancara kepada pengurus PSBG terdapat 5 masalah yang dihadapi mitra, antara lain: (1) Kemampuan guru dalam membuat alat peraga dan katalognya sangat rendah; (2) Pemanfaatan IT yang terdapat di PSBG sangat jarang; (3) RPP yang dibuat guru belum memasukkan berbagai model pembelajaran; dan (4) Guru belum mampu membuat majalah bulanan PSBG. Berdasarkan permasalahan tersebut ditawarkan beberapa solusi, antara lain: (1) pelatihan dan pendampingan pembuatan media pembelajaran serta katalognya; (2) pelatihan dan pendampingan pembuatan media berbasis IT; (3) pelatihan dan pendampingan pembuatan RPP dengan berbagai model pembelajaran; dan (4) pelatihan dan pendampingan pembuatan majalah bulanan PSBG. Target khusus dan luaran yang akan dihasilkan adalah: (1) Catalog media pembelajaran; (2) Kumpulan media pembelajaran berbasis IT; (3) Buku kumpulan rubrik penilaian. Metode pelaksanaan program pengabdian akan dilakukan secara bertahap, berkelanjutan, dan komprehensif yang dilaksanakan melalui metode supervisi klinis dalam upaya mengembangkan kemampuan dan keterampilan mengelola dan memberdayakan keberlangsungan PSBG .
\end{abstract}

Kata Kunci: Revitalisasi, Pusat Sumber Belajar Gugus, Berbasis IT 

PENDAHULUAN

Pendidikan adalah usaha sadar yang dilakukan secara terencana, sistematis dengan tujuan untuk menambah wawasan serta pengetahuan merubah sikap dan keterampilan melalui sebuah aktifitas atau pembiasaan. Faktor kunci penentu kualitas dan mutu pendidikan adalah guru. Sebagai tenaga pendidik, guru adalah modal dasar untuk meningkatkan mutu proses pembelajaran pada tingkat kelas. Kualitas guru akan sangat menentukan tinggi rendahnya kualitas suatu proses pembelajaran. Oleh karena itu, upaya peningkatan kualitas dan kualifikasi pendidikan para guru sebagai bagian integral dari proses peningkatan kualitas pendidikan secara keseluruhan di Indonesia perlu dilakukan secara terencana, terarah dan berkesinambungan.

Pusat Sumber Belajar Gugus (PSBG) merupakan sebuah wadah yang sengaja dirancang, di gagas untuk dibuat di setiap gugus yang berada di sekolah yang bertujuan untuk menjadi bengkel bagi guru dalam merencanakan, merancang segala sesuatu yang berhubungan dengan kegiatan belajar mengajar yang akan dilakukannya di dalam kelas. Selain itu pusat sumber belajar gugus juga diharapkan dapat menjadi tempat pertemuan dan sebagai sarana memperoleh informasi bagi guru dalam melaksanakan segala tugasnya di sekolah masing- masing. Pusat seumber belajar gugus juga diharapkan menjadi wadah bagi guru dalam meningkatkan

keprofesionalannya.

PSBG mempunyai 4 fungsi utama yang jika dapat dikelola dengan baik dan mampu dilaksanakan oleh guru-guru dalam gugus maka akan dapat meningkatkan kompetensi dan keprofesionalan guru sebagai tanaga pendidik. Ke empat fungsi PSBG adalah sebabagi berikut: (a) pertemuan, (pengembangan profesi, (c) informasi, dan (d) produksi.

Kota Tebingtinggi memiliki dua Pusat sumber belajar gugus (PSBG). Ke dua PSBG tersebut yaitu PSBG STUDY CENTER dan PSBG Taman Kreatif. Kondisi ke dua PSBG tersebut saat ini setelah dilaksanakannya kegiatan pendampingan yang pertama sudah berjalan walaupun belum begitu maksimal. Guru dan stakeholder lainnya belum mampu merancang sebuah kegiatan yang dapat menciptakan sesuatu yang istimewa. Kegiatan yang sudah berjalan di PSBG saat ini baru hanya sebatas memanfaatkan sarana dan prasarana yang tersedia di PSBG. Fungsi yang terlihat sangat dominan dalam pemanfaatan PSBG adalah fungsi PSBG sebagai tempat pertemuan dan informasi, Fungsi produksi dan pengembangan professional belum dapat terlihat dengan jelas dilaksanakan oleh manager maupun stakeholder lainnya. Walaupun demikian bisa dikatakan PSBG sudah mulai menunjukkan aktifitasnya jika dibandingkan beberapa saat sebelum kegiatan pendampingan dilaksanakan dimana 
Eva Betty Simanjuntak, Dewi Syafriani : Pusat Sumber ...

PSBG tersebut sama sekali tidak termanfaatkan

Hasil wawancara yang

dilakukan kepada pengelola PSBG STUDY CENTER dan PSBG TAMAN KREATIF yang baru terpilih, ditemukanlah gambaran bahwa kemampuan dan kreatifitas guru dan pengelola di kedua PSBG tersebut dalam upaya memasyarakatkan dan memberdayakan PSBG sebagai sanggar belajar guru baru hanya sebatas aktifitas pemahaman dan pengenalan berbagai kebutuhan yang mendasar bagi guru saja. Guru dan stakeholder lainnya belum mampu memanfaatkan berbagai sarana dan menjadikan PSBG sebagai bengkel penempah guru yang professional sampai pada tingkatan mencipta atau mengkreasi berbagai sarana dan prasarana yang terdapat di PSBG sehingga dapat menjadi bahan yang nantinya dimanfaatkan oleh teman teman guru yang lain dalam proses pembelajaran di dalam kelas.

Berdasarkan permasalahan khusus yang di gambarkan di atas dan hasil diskusi yang dilakukan oleh tim dengan manager PSBG STUDY CENTER dan PSBG TAMAN KREATIF disepakatilah permasalahan yang menjadi prioritas di kedua PSBG kota Tebingtinggi. Adapun permasalahan prioritas dari ke dua PSBG tersebut adalah:

a. Belum adanya terlihat catalog dan media/alat peraga pembelajaran yang dihasilkan oleh guru-guru dan stakeholder lainnya di PSBG.

b. Tidak adanya media pembelajaran berbasis IT (power point, flash dll) yang dihasilkan di PSBG.

c. RPP yang dibuat guru di PSBG baru bersifat copy paste dari internet atau RPP guru lain dan belum memasukkan berbagai model pembelajaran dalam kegiatan pembelajarannya.

d. Rendahnya kemampuan guru dalam menyusun dan membuat rubrik penilaian.

e. Tidak adanya dokumentasi dan publikasi terhadap keberhasilan guru-guru yang telah mencoba melakukan proses yang baik dalam pembelajaran (best Practise) sebagai motivasi dan rangsangan bagi guru yang lain agar coba menirunya

Berdasarkan permasalahan yang di gambarkan di atas dan hasil diskusi yang dilakukan oleh tim pengabdi dengan manager PSBG STUDY CENTER dan PSBG TAMAN KREATIF disepakatilah permasalahan yang menjadi prioritas pemecahannya, solusi dan luaran yang akan di berikan bagi kedua PSBG tersebut. Adapun permasalahan, solusi dan luaran yang ditawarkan pada kegiatan ini terlihat seperti pada tabel berikut: 
SCHOOL EDUCATION JOURNAL VOLUME 8 NO. 3 DESEMBER 2018

Tabel 1. Permasalahan, Solusi dan Luaran Pengabdian

\begin{tabular}{|c|c|c|c|}
\hline No & Permasalahan & Solusi & luaran \\
\hline 1 & $\begin{array}{l}\text { Belum adanya terlihat catalog dan } \\
\text { media / alat peraga pembelajaran } \\
\text { yang dihasilkan oleh guru-guru } \\
\text { dan stakeholder lainnya di PSBG }\end{array}$ & $\begin{array}{l}\text { Pelatihan dan } \\
\text { pendampingan pembuatan } \\
\text { alat peraga / media } \\
\text { pembelajaran }\end{array}$ & $\begin{array}{l}\text { Catalog alat peraga / } \\
\text { media pembelajaran }\end{array}$ \\
\hline 2 & $\begin{array}{l}\text { Tidak adanya media pembelajaran } \\
\text { berbasis IT } \\
\text { ( power point, flash dll) yang } \\
\text { dihasilkan di PSBG. }\end{array}$ & $\begin{array}{l}\text { Pelatihan dan } \\
\text { pendampingan pembuatan } \\
\text { media pembelajaran } \\
\text { berbasis IT }\end{array}$ & $\begin{array}{l}\text { Kumpulan media } \\
\text { pembelajaran berbasis } \\
\text { IT ( power point, flash } \\
\text { dll ) }\end{array}$ \\
\hline 3 & $\begin{array}{l}\text { RPP yang dibuat guru di PSBG } \\
\text { baru bersifat copi paste dari } \\
\text { internet atau RPP guru lain dan } \\
\text { belum memasukkan berbagai } \\
\text { model pembelajaran dalam } \\
\text { kegiatan pembelajarannya }\end{array}$ & $\begin{array}{l}\text { Pelatihan dan } \\
\text { pendampingan pembuatan } \\
\text { RPP dengan menggunakan } \\
\text { berbagai model } \\
\text { pembelajaran }\end{array}$ & $\begin{array}{l}\text { Buku kumpulan RPP } \\
\text { pembelajaran dengan } \\
\text { menggunakan berbagai } \\
\text { model pembelajaran }\end{array}$ \\
\hline 4 & $\begin{array}{l}\text { Rendahnya kemampuan guru } \\
\text { dalam menyusun dan membuat } \\
\text { rubric penilaian. }\end{array}$ & $\begin{array}{l}\text { Pelatihan dan } \\
\text { pendampingan pembuatan } \\
\text { rubric penilaian }\end{array}$ & $\begin{array}{l}\text { Buku kumpulan rubric } \\
\text { penilaian }\end{array}$ \\
\hline 5 & $\begin{array}{l}\text { Tidak adanya dokumentasi dan } \\
\text { publikasi terhadap keberhasilan } \\
\text { guru-guru yang telah mencoba } \\
\text { melakukan proses yang baik } \\
\text { dalam pembelajaran ( best } \\
\text { Practise ) sebagai motivasi dan } \\
\text { rangsangan bagi guru yang lain } \\
\text { agar coba menirunya }\end{array}$ & $\begin{array}{l}\text { Pelatihan dan } \\
\text { pendampingan pembuatan } \\
\text { majalah bulanan PSBG }\end{array}$ & Majalah bulanan PSBG \\
\hline
\end{tabular}

\section{METODE PENELITIAN}

Metode pelaksanaan kegiatan dilaksanakan berdasarkan permasalahan-permasalahan PSBG sebagaimana digambarkan oleh manager PSBG seperti yang dipaparkan sebelumnya. Dalam upaya mencapai tujuan kegiatan pengabdian ini, maka rancangan pada kegiatan ini adalah perencanaan (planning), pelaksanaan (action), refleksi (reflection) dan tindak lanjut (follow up). Secara spesifik mekanisme pelaksanaan kegiatan ini diuraikan sebagai berikut. a. Identifikasi permasalahan dan kebutuhan PSBG

b. Kesepakatan dua mitra melalui penandatanganan surat pernyataan dukungan pelaksanaan kegiatan.

c. Tim pengabdi menyusun rencana pendampingan yang akan dilakukan.

d. Melaksanakan kegiatan pelatihan dan pendampingan yang dilaksanakan di PSBG. Kegiatan pelatihan dan pendampingan yang dilaksanakan meliputi : 
Eva Betty Simanjuntak, Dewi Syafriani : Pusat Sumber ...

- Pelatihan dan pendampingan pembuatan alat peraga/ media pembelajaran

- Pelatihan dan pendampingan pembuatan media pembelajaran berbasis IT

- Pelatihan dan pendampingan pembuatan RPP

- Pelatihan dan pendampingan pembuatan rubric penilaian

- Pelatihan dan pendampingan pembuatan majalah bulanan PSBG

e. Melakukan evaluasi dan refleksi untuk mengetahui sejauhmana keberhasilan dari pelaksanaan kegiatan pendampingan

f. Tindak lanjut dalam kegiatan ini yaitu pembuatan artikel.

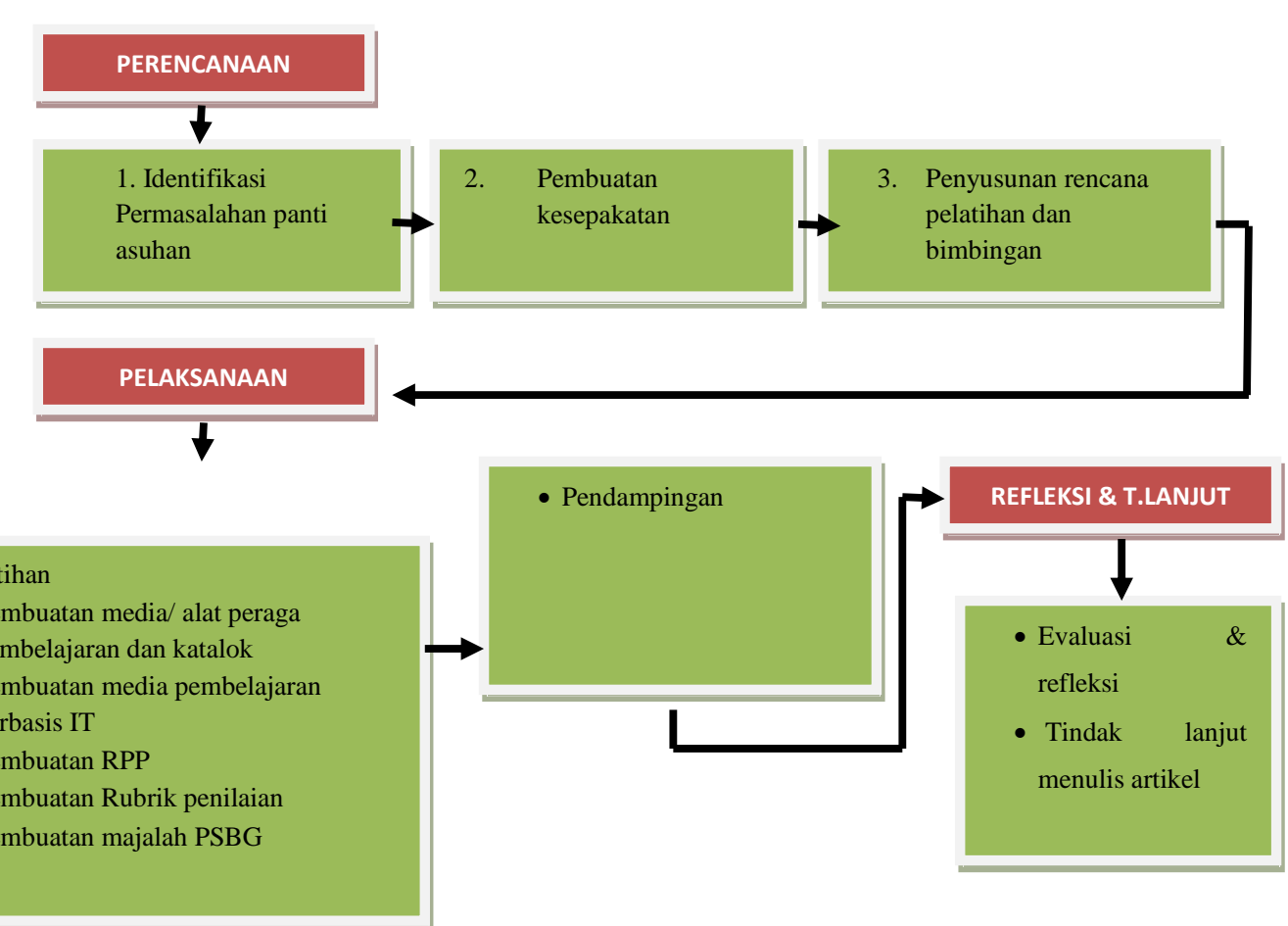

Gambar 1. Skematik Metode Pelaksanaan

Metode pendekatan harus disesuaikan dengan permasalahan dan terget capaian setiap kegiatan.

Beberapa metode yang dapat 
digunakan dalam pengabdian ini antara lain: pelatihan, pendampingan, simulasi, wawancara, catatan lapangan, observasi, dan kerjasama. Setiap metode diaplikasikan berdasarkan tujuan kegiatan yang ingin dicapai. Evaluasi pengabdian revitalisasi Pusat Sumber Belajar Gugus (PSBG) kota Tebingtinggi provinsi Sumatera Utara dilakukan pada beberapa tahap dari kegiatan, yaitu: Pada awal kegiatan evaluasi dilakukan untuk mengetahui sampai sejauh mana implementasi dan aktifitas PSBG setelah mendapatkan kegiatan pendampingan. Dari hasil evaluasi di awal kegiatan terlihat bahwa pemanfaatan PSBG belumlah optimal sebagaimana yang diharapkan sesuai dengan 4 fungsi PSBG.

Selanjutnya evaluasi juga dilakukan saat kegiatan berlangsung untuk mengetahui sudah sampai sejauh mana pemahaman stakeholder PSBG terhadap materi yang telah disampaikan sehingga jika masih ada yang belum dapat dipahami akan lebih diberikan penguatan pada materi-materi tersebut. Di akhir pengabdian evaluasi dilakukan secara menyeluruh untuk melihat hasil dari pengabdian yang telah dilakukan. Tim akan melihat keberhasilan kegiatan dibuktikan dengan luaran yang di dapat dari hasil kegiatan. Hasil dari evaluasi akan di bandingkan dengan evaluasi diawal kegiatan sebelum kegiatan dilakukan. Diharapkan dengan evaluasi yang telah dilakukan kemampuan stakeholder bertambah meningkat sehingga 4 fungsi PSBG dapat terlaksana secara optimal sehingga pendidikan di kota Tebingtinggi menjadi lebih baik dan meningkat.

Pengabdian kepada Masyarakat dilakukan secara periodik dan profesional oleh LPM Unimed melalui dana PNBP, BOPTN, dana kerjasama, maupun dana CSR dari perusahaan kepada masyarakat yang memerlukan. Berbagai bentuk pengabdian kepada masyarakat oleh civitas academica Unimed pada dasarnya merupakan bentuk pengamalan ipteks dan hasil-hasil penelitian perguruan tinggi kepada masyarakat. Unimed merupakan lembaga pendidikan dan pengembangan IPTEKS yang dalam pencapaian keberhasilan otonomi daerah memiliki posisi yang sentral. Satu hal yang diupayakan oleh Unimed dan pemerintah daerah adalah menyamakan persepsi antara kalangan sivitas akademik, unsur pemerintah daerah, dan seluruh stakeholders, serta segenap lapisan masyarakat tentang fungsi perguruan tinggi itu dalam membangun masyarakat dan bangsa.

LPM Unimed telah bekerjasama dengan beberapa sekolah dalam kegiatan peningkatan kemampuan guru dan siswa dalam menyelesaikan soal olimpiade sains. Selanjutnya LPM Unimed juga melakukan Pengembangan Budaya Kewirausahaan yang merupakan kegiatan untuk mengembangkan budaya kewirausahaan di kalangan sivitas akademika perguruan tinggi 
dan masyarakat sekitar/desa binaan.

Berbagai kegiatan yang telah dilakukan antara lain: Kuliah Kewirausahaan, Magang Kewirausahaan, Kuliah Kerja Usaha, Inkubator Wirausahawan Baru, dan Konsultasi Bisnis dan Penempatan Kerja. Aktivitas lain yang juga telah dilakukan oleh LPM Unimed adalah Pengembangan dan Penerapan Hasil Penelitian yang telah dilakukan oleh dosen. Telah dilakukan rekayasa metoda mengajar dan penciptaan alat-alat peraga yang relevan dengan sosial budaya anak didik di Sumatera Utara misalnya, dapat dikembangkan melalui kegiatan-kegiatan penelitian dengan pendekatan Research and Development. Unimed juga telah melakukan pengembangan dan penerapan hasil penelitian berupa penelitian Kaji Tindak (Action Research). Selanjutnya, Unimed juga telah melakukan pembinaan guru dalam melaksanakan Penelitian Tindakan Kelas dalam upaya pengembangan profesionalisme guru.

Melihat permasalahan yang akan diselesaikan pada pengabdian revitalisasi pusat sumber belajar gugus (PSBG) kota Tebingtinggi, jenis kepakaran yang diperlukan antara lain: (a) ahli pembuatan media pembelajaran, (b) ahli merancang media pembelajaran berbasis IT, (c) ahli perancangan pembelajaran dan penilaian, dan (d) ahli publikasi dan informasi.

\section{HASIL PENELITIAN DAN PEMBAHASAN}

Hasil yang dicapai dalam kegiatan pengabdian ini dimulai dari usaha persiapan kegiatan yang telah dimulai dari bulan Mei 2018. Beberapa hal yang dilakukan dan dihasilkan adalah

a. Setting persiapan kegiatan pengabdian yang dimulai dari pengaturan tugas tim, koordinasi dengan unsur-unsur Lembaga Pengabdian Masyarakat Unimed dan penguatan kesepakatan dengan sekolah mitra pengabdian untuk menyatukan pandangan tentang rencana dan prosedur pelaksanaan penelitian.

b. Penguatan dan penandatanganan MoU dan pengurusan perizinan dengan pihak manager PSBG Study Center dan PSBG Taman Kreatif.

c. Pembuatan modul revitalisasi PSBG dan penggandaan modul

d. Jadwal agenda pendampingan pengelolaan PSBG

Setelah dilakukan analisis awal permasalahan terhadap PSBG Study Center dan PSBG Taman Kreatif maka selanjutnya dilakukan bebrerapa tahapan pelaksanaan pengabdian berupa workshop dan kegiatan pendampingan di PSBG Study Center dan PSBG Taman Kreatif. Pada kegiatan pelatihan dan pendampingan pembuatan media dan catalog pembelajaran, pengelola PSBG dibekali dengan penjelasan tentang pentingnya media dan karakteristik berbagai media 
pembelajaran. Selanjutnya pengelola PSBG diberikan berbagai contoh tentang media pembelajaran dan cara pemanfaatannya dalam proses pembelajaran di kelas. Selanjutnya pada kegiatan pendampingan ini, pengelola PSBG dilatih untuk merancang media pembelajaran sederhana dengan menggunakan berbagai bahan yang banyak dijumpai disekitar sekolah dan rumah. Selain itu dipilih juga media yang dari sisi biaya murah, mudah dan tidak berbahaya bagi siswa dan guru itu sendiri. Setelah media pembelajaran dirancang oleh pengelola, selanjutnya pengelola dilatih bagaimana cara membuat catalog dari media pembelajaran yang telah dirancang.

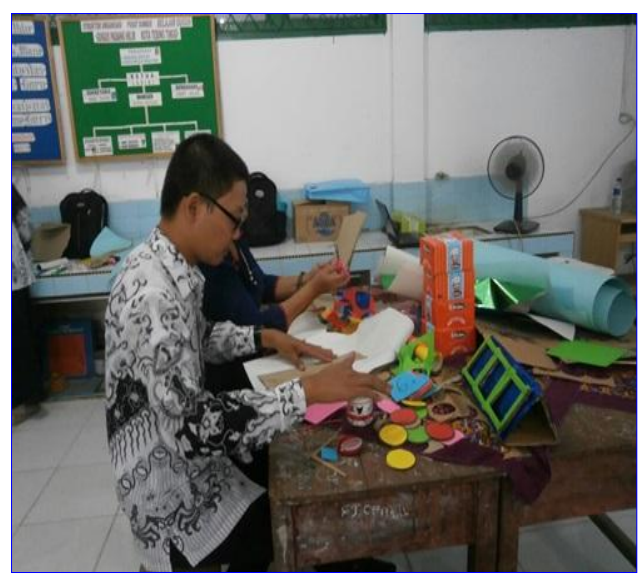

\section{Gambar 2. Peserta sedang membuat} media dan katalog

Kegiatan pelatihan dan pendampingan pembuatan media berbasis IT ini bertujuan untuk membekali guru dan stakeholder pendidikan lainnya dalam hal pembuatan media pembelajaran dengan memanfaatkan fasilitas IT yang terdapat di PSBG. Hal ini dirasa perlu dikarenakan pemanfaatan fasilitas IT yang terdapat di PSBG begitu jarang tersentuh oleh kalangan pengguna PSBG. Guru dan stakeholder lainnya merasa tidak mampu dan tidak memiliki keterampilan dalam menggunakan fasilitas IT dan memanfaatkannya untuk menjadi media pembelajaran di dalam kelas.

Pada kegiatan pelatihan dan pendampingan ini guru dan stakeholder lainnya dibekali dan dilatih membuat berbagai media pembelajaran seperti power point, flash dan video pembelajaran yang diharapkan dipergunakan saat proses belajar mengajar di kelas.

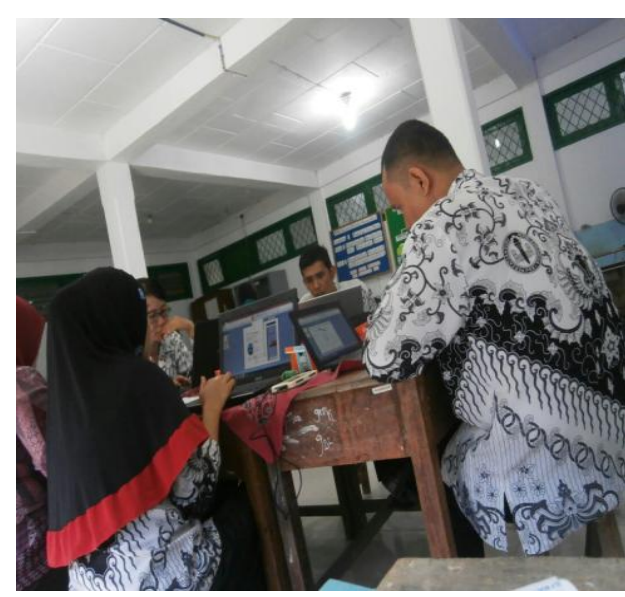

Gambar 3. Peserta sedang membuat media pembelajaran berbasis IT

Salah satu kelemahan dan kendala guru selama ini adalah ketidakmampuan guru dalam membuat sebuah perencanaan yang baik yang akan dipergunakan dalam proses belajar mengajar. Seorang guru wajib menyusun sebuah perencanaan yang akan dilakukan 
dalam proses pembelajaran terhadap anak muridnya di dalam kelas. Perencanaan yang perlu dimiliki oleh seorang guru adalah RPP. Selama ini RPP yang dipergunakan oleh guru adalah RPP yang diambil dari internet, atau RPP copi paste dari teman guru yang berada di sekolah lain. Masih banyak guru lemah dalam menyusun RPP, sehingga proses belajar mengajar di kelas menjadi monoton dan sangat membosankan siswanya.

Kegiatan dan pendampingan dalam menyusun RPP ini bertujuan untuk memberikan pemahaman dan wawasan kepada peserta tentang berbagai model pembelajaran yang dapat dimanfaatkan dan dimasukkan ke dalam RPP yang dibuat sehingga dapat memberikan kesegaran kepada siswa dalam proses memperoleh ilmu dari gurunya. Pada kegiatan ini guru dan peserta diperkenalkan dengan berbagai model pembelajaran yang sederhana, gampang melaksanakannya dan tidak membutuhkan biaya besar dalam menerapkannya di dalam kelas. Guru dan peserta pelatihan dibimbing dalam merancang dan memperaktekkan pelaksanaan model pembelajaran dalam kelas kecil dengan tujuan melihat kemampuan peserta dan memberikan masukan terhadap kekurangan yang terlihat.

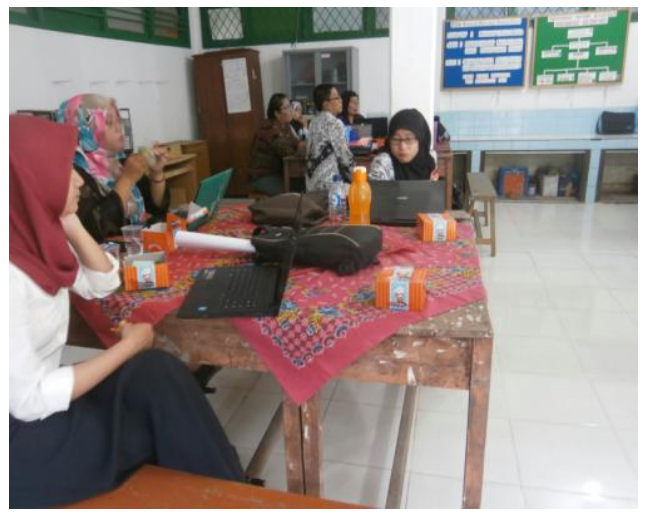

\section{Gambar 4. Peserta Mendengarkan Penjelasan tentang Model-model Pembelajaran}

Kegiatan workshop dan pendampingan penyusunan rubrik penilaian dihadiri sebanyak 20 sekolah mitra PSBG Study Center dan PSBG Taman Kreatif yang dalam hal ini diwakili oleh kepala sekolah dan 1 orang guru. Selain itu hadir juga pengurus dan pengelola PSBG Study Center dan PSBG Taman Kreatif yang telah berakhir masa baktinya beberapa tahun yang lalu. Kegiatan workshop penyusunan rubric penilaian ini berjalan dengan lancar dan sukses. Hasil dari workshop pengelolaan PSBG ini adalah bertambahnya pemahaman peserta tentang tata cara dan manfaat penyusunan rubric penilaian. Selanjutnya dari hasil rubric yang disusun peserta dibuatlah buku rubric penilaian yang akan menjadi acuan bagi guru-guru mitra PSBG dalam menyusun rubrik penilaian. 


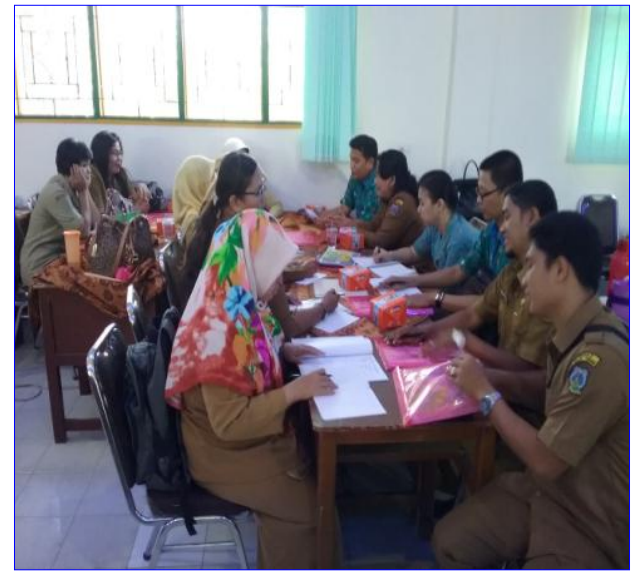

Gambar 5. Peserta sedang menyusun rubrik penilaian

Pelatihan dan pendampingan ini bertujuan untuk membantu pengurus dan manager PSBG dalam mendokumentasikan dan mempublikasikan berbagai kegiatan PSBG agar dapat diketahui oleh seluruh guru dan stakeholder lainnya. Pengurus PSBG akan diberikan keterampilan dalam menyusun majalah bulanan PSBG. Melalui pendampingan ini diharapkan pengurus memiliki keterampilan dalam pembuatan majalah dan kedepan dengan majalah yang telah dibuat diharapkan makin banyak guru yang akan mengunjungi dan memanfaatkan PSBG sebagai bengkel kreatifitas guru.

\section{SIMPULAN}

a. Kegiatan Revitalisasi Pusat Sumber Belajar Gugus (PSBG) kota Tebingtinggi telah membawa dampak yang positif terhadap keberlanjutan kegiatan di PSBG Study Center dan PSBG Taman Kreatif kota Tebingtinggi b. Hasil workshop dan pendampingan yang telah dilakukan telah menghasilkan luaran : (1) buku kumpulan rubric penilaian, (2) buku RPP yang memuat berbagai modelmodel pembelajaran, dan (3) berbagai media/alat peraga serta katalognya yang dapat dimanfaatkan oleh guru dalam merancang dan melaksanakan proses pembelajaran di dalam kelas.

c. Pengelola PSBG secara kontiniu selalu mengingatkan guru-guru yang berada di wilayah kerja PSBG untuk dapat mengunjungi PSBG dan memanfaatkan berbagai sumber belajar yang terdapat di PSBG

d. Manager dan pengelola PSBG perlu terus meningkatkan kompetensi dan keprofesionalismeannya agar dapat membantu guru yang datang ke PSBG dengan cara mandiri maupun secara kolektif.

\section{DAFTAR RUJUKAN}

Kemdikbud. 2013. Panduan Pelaksanaan Penelitian dan Pengabdian Kepada Masyarakat di Perguruan Tinggi (Edisi IX). Jakarta.

Peraturan Pemerintah RI Nomor 74 Tahun 2008. Tentang Guru (Lembaran Negera RI Tahun 2008 Nomor 194).

Tim penyusun. 2013. Panduan Pelaksanaan Penelitian dan Pengabdian Kepada Masyarakat Di Perguruan 
Eva Betty Simanjuntak, Dewi Syafriani : Pusat Sumber ...

Tinggi Edisi IX. Direktorat

Penelitian dan Pengabdian

Kepada Masyarakat Direktorat

Jenderal Pendidikan Tinggi

Kementerian Pendidikan Dan

Kebudayaan.

USAID. 2009. Pengelolaan Pusat

Sumber Belajar Gugus

(PSBG), [Modul Pelatihan],

Jakarta: DBE-2. 